\title{
Long non-coding RNA mortal obligate RNA transcript suppresses tumor cell proliferation in prostate carcinoma by inhibiting glucose uptake
}

\author{
ZHENFENG SHI $^{1 *}$, FENG GUO ${ }^{1 *}$, DEYONG JIA ${ }^{2}$, JINXING HUANG $^{3}$, \\ JIE CHEN ${ }^{4}$, MIN SUN $^{1}$, FEIBO QI ${ }^{1}$ and CHENGYUAN LIANG ${ }^{5}$ \\ ${ }^{1}$ Department of Urology, The People's Hospital of Xinjiang Uyghur Autonomous Region, Urumqi, \\ Xinjiang Uygur Autonomous Region 830002, P.R. China; ${ }^{2}$ Department of Urology, University of Washington, \\ Seattle, WA 98109, USA; ${ }^{3}$ Department of Urology, The People's Hospital of Shache County, Kashi, \\ Xinjiang Uygur Autonomous Region 844700; ${ }^{4}$ Department of Radiography, The People's Hospital of \\ Xinjiang Uyghur Autonomous Region, Urumqi, Xinjiang Uygur Autonomous Region 830002; \\ ${ }^{5}$ Department of Pharmacy, Shaanxi University of Science and Technology, \\ Xi'an, Shaanxi 710021, P.R. China
}

Received October 23, 2018; Accepted July 30, 2019

DOI: $10.3892 / \mathrm{ol} .2019 .10711$

\begin{abstract}
A previous study reported the decreased expression of long non-coding RNA mortal obligate RNA transcript (lncRNA MORT) in 16 types of cancer, while the functionality of lncRNA MORT in cancer biology remains unknown. Therefore, the present study was conducted to characterize the functionality of IncRNA MORT in prostate carcinoma, a common cancer type worldwide. IncRNA MORT expression level was downregulated in tumor tissues compared with that in the adjacent healthy tissues of patients with prostate carcinoma. Expression of lncRNA MORT in tumor tissues was influenced by tumor size, but not by tumor metastasis. Overexpression of IncRNA MORT inhibited glucose uptake and glucose transporter 1 (GLUT-1) expression in prostate carcinoma cell lines; GLUT-1 overexpression upregulated glucose uptake and attenuated the effects of IncRNA MORT overexpression
\end{abstract}

Correspondence to: Dr Feibo Qi, Department of Urology, The People's Hospital of Xinjiang Uyghur Autonomous Region, 91 Tianchi Road, Tianshan, Urumqi, Xinjiang Uygur Autonomous Region 830002, P.R. China

E-mail: ej05085@163.com

Dr Chengyuan Liang, Department of Pharmacy, Shaanxi University of Science and Technology, 111, Xiandao, Weiyangdaxueyuanqu, Xi'an, Shaanxi 710021, P.R. China

E-mail: iyc8293@163.com

${ }^{*}$ Contributed equally

Key words: prostate carcinoma, long non-coding RNA mortal obligate RNA transcript, glucose uptake, glucose transporter 1 on glucose uptake, but did not significantly affect the expression of IncRNA MORT. Overexpression of lncRNA MORT inhibited, while GLUT-1 overexpression promoted the proliferation of prostate carcinoma cells. In addition, GLUT-1 overexpression attenuated the effects of lncRNA MORT on cell proliferation. Therefore, lncRNA MORT may inhibit cancer cell proliferation in prostate carcinoma by preventing glucose uptake.

\section{Introduction}

As a type of cancer that originates from the prostate, a gland of the male reproductive system, prostate carcinoma is one of the most frequently diagnosed and leading causes of cancer associated-mortality in males (1). The early stages of prostate carcinoma development lack classic cancer symptoms, leading to a high prevalence of tumor metastasis by the time of diagnosis (2). However, patients in the advanced stages of disease exhibit difficulty in urinating, pain in the pelvis and back when urinating, in addition to blood in the urine (3). In spite of efforts to improve treatment of the disease, the mortality rate of prostate carcinoma remains high $(4,5)$.

Due to the abnormally accelerated proliferation of cancer cells, which requires increased energy input, glucose metabolism is considered to be a promising therapeutic target for cancer therapy $(6,7)$. In mammalian cells, glucose transporter 1 (GLUT-1) mediates the transport of glucose across the plasma membrane (8). GLUT-1 is reportedly overexpressed in the majority of, if not all human cancers (including prostate carcinoma) and the iinhibition of GLUT-1 resulted in the inhibited growth of cancer cells (9). A growing body of literature has revealed that GLUT-1 may participate in the development and progression of cancer by interacting with long non-coding RNAs (lncRNAs) (10), a group of non-coding RNA transcripts 
$>200$ nucleotides, associated with cancer biology (11). Despite a recent report of the reduced expression of IncRNA MORT in 16 types of cancer (12), the functionality of lncRNA MORT in cancer remains unknown. The present study aimed to investigate the involvement of IncRNA MORT in prostate carcinoma, and its potential interaction with glucose uptake pathways.

\section{Materials and methods}

Human specimens and cell lines. Tumor and adjacent healthy tissue specimens were obtained from 60 male patients with prostate carcinoma who were admitted to the People's Hospital of Xinjiang Uyghur Autonomous Region (Urumqi, China) between February 2016 and March 2018. The inclusion criteria were as follows: i) Patients were diagnosed by pathological biopsy; ii) patients had complete medical records; and iii) patients were willing to cooperate with researchers, and gave written informed consent. Exclusion criteria: i) Patients with other diseases; ii) patients who could not understand the experimental protocol; and iii) patients had received treatment within 3 months of admission. The patient age range was between $34-70$ years (mean, $49.3 \pm 6.1$ years). There were 10 cases of stage I, 12 cases of stage II, 18 cases of stage III and 20 cases of stage IV cancer. Tumor sizes were determined using magnetic resonance imaging (GE Signa HDxt 1.5T, GE, USA). The present study was approved by the Ethics committee of the People's Hospital of Xinjiang Uyghur Autonomous Region, and all participants gave written informed consent to participate.

Cells of the human prostate carcinoma cell line 22Rv1 were purchased from the American Type Culture Collection (ATCC, Manassas, VA, USA), and cultured in Dulbecco's Modified Eagle's medium supplemented with $10 \%$ fetal bovine serum (cat. no. 30-2020; ATCC) at $37^{\circ} \mathrm{C}, 5 \% \mathrm{CO}_{2}$.

Reverse transcription-quantitative polymerase chain reaction $(R T-q P C R)$. TRIzol $^{\circledR}$ reagent (Thermo Fisher Scientific, Inc., Waltham, MA, USA) was used to extract total RNA from the tissue specimens and cells. Tissues retrieved from liquid nitrogen were ground up prior to the addition of TRIzol reagent, whilst $22 \mathrm{Rv} 1$ cells were directly mixed with the reagent to extract total RNA. Following reverse transcription using the High-Capacity cDNA Reverse Transcription kit (Applied Biosystems $^{\mathrm{TM}}$; Thermo Fisher Scientific, Inc.), PCR reactions were prepared using the SYBR ${ }^{\circledast}$ Green Quantitative RT-qPCR kit (Sigma-Aldrich; Merck KGaA, Darmstadt, Germany). CFX96 Touch Real-Time PCR Detection system (Bio-Rad Laboratories, Inc.) was used to perform all qPCR reactions. Three replicates were set for each reaction. RT and PCR steps were conducted according to the manufacturer's protocol. Primers for lncRNA MORT and $\beta$-actin were designed and synthesized by Sangon Biotech Co., Ltd. (Shanghai, China). The primer sequences were as follows: IncRNA MORT forward, 5'-GTTGTAGCATGCATCAGAAC-3', and reverse, 5'-CAGGACACCCAACAGCCCAA-3'; GLUT-1 forward, 5'-CAGTTCGGCTATAACACTGGT-3', and reverse, 5'-GCC CCCGACAGAGAAGAT-3'; $\beta$-actin forward, 5'-GACCTC TATGCCAACACAGT-3', and reverse, 5'-AGTACTTGCGCT CAGGAGGA-3'. Thermocycling conditions were as follows: $95^{\circ} \mathrm{C}$ for $1 \mathrm{~min}$, and then 40 cycles of $95^{\circ} \mathrm{C}$ for $10 \mathrm{sec}, 55^{\circ} \mathrm{C}$ for

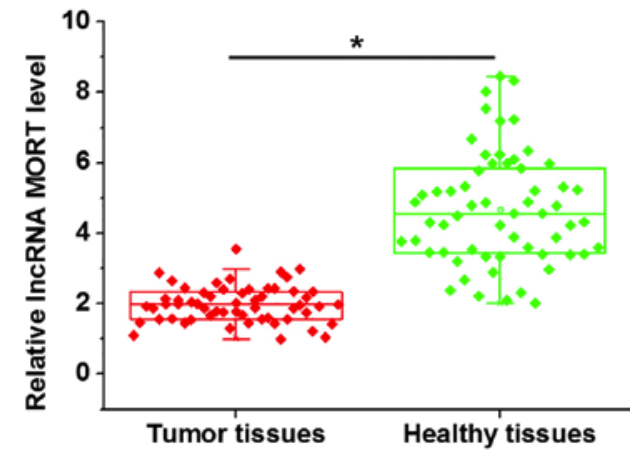

Figure 1. IncRNA MORT is downregulated in tumor tissues compared with the adjacent healthy tissues of patients with prostate carcinoma. Reverse transcription-quantitative polymerase chain reaction determined that, compared with adjacent healthy tissues, the expression levels of lncRNA MORT were significantly downregulated in tumor tissues. ${ }^{*} \mathrm{P}<0.05$. IncRNA MORT, long non-coding RNA mortal obligate RNA transcript.

$30 \mathrm{sec}$ and $72^{\circ} \mathrm{C}$ for $30 \mathrm{sec}$. The expression level of lncRNA MORT was normalized to that of the endogenous $\beta$-actin control using the $2^{-\Delta \Delta \mathrm{Cq}}$ method (13).

Transfection. The pSF-MinCMV-KrYFP vector expressing lncRNA MORT or GLUT-1, and the empty control vector were designed and synthesized by Sangon Biotech Co., Ltd. The 22Rv1 cell line was cultivated overnight to reach $70-80 \%$ confluence. Lipofectamine $2000^{\circledR}$ (cat. no. $11668-019$, Invitrogen; Thermo Fisher Scientific, Inc.) was used to transfect $10 \mathrm{nM}$ vector into $5 \times 10^{5}$ cells/sample. Negative control cells were transfected with empty vector, and control cells were treated with Lipofectamine 2000 only. In cases of co-transfection, $10 \mathrm{nM}$ MORT and $10 \mathrm{nM}$ GLUT-1 vectors were transfected at the same time. Following experiments were performed at $24 \mathrm{~h}$ post-transfection.

Glucose uptake assay. Cell glucose uptake was assessed only in cases in which the overexpression rate of IncRNA MORT reached $200 \%$ (determined using RT-qPCR). Briefly, to initiate glucose uptake, $22 \mathrm{Rv} 1$ cells $\left(3 \times 10^{5}\right.$ cells harvested at $24 \mathrm{~h}$ post-transfection) were washed with PBS, and incubated with $10 \mathrm{ml}$ Krebs-Ringer-HEPES (KRH) buffer $(120 \mathrm{mM}$ $\mathrm{NaCl}, 1.2 \mathrm{mM} \mathrm{MgSO}$, $25 \mathrm{mM}$ HEPES pH 7.4, $1.3 \mathrm{mM}$ $\mathrm{CaCl}_{2}, 1.3 \mathrm{mM} \mathrm{KH}_{2} \mathrm{PO}_{4}$ and $5 \mathrm{mM} \mathrm{KCl}$ ) containing $1 \mu \mathrm{Ci}$ of $\left[{ }^{3} \mathrm{H}\right]$-2-deoxyglucose at $37^{\circ} \mathrm{C}$ for $30 \mathrm{~min}$. Cells were subsequently washed with ice-cold KRH buffer to terminate glucose uptake, and lysed (10 mM Tris-HCl, pH 8.0, 0.2\% SDS) prior to the measurement of radioactivity using liquid scintillation spectrometry using 1220 QUANTULUS Ultra Low Level Liquid Scintillation Spectrometer (PerkinElmer, Inc.). Glucose uptake was presented as disintegrations per minute (DPM).

Cell proliferation assay. Cell proliferation was detected only in cases in which the overexpression rate of IncRNA MORT reached $200 \%, 24$ h post-transfection. Briefly, cells were collected $24 \mathrm{~h}$ post-transfection, and single $0.1 \mathrm{ml}$ cell suspensions per well $\left(4 \times 10^{4}\right.$ cells $\left./ \mathrm{ml}\right)$ were transferred to a 96 -well plate. Cells were cultured at $37^{\circ} \mathrm{C}$ and $10 \mu \mathrm{l}$ Cell Counting Kit-8 solution (Sigma-Aldrich; Merck KGaA) was added at 24, 48, 72 and $96 \mathrm{~h}$. Cells were cultured for an additional 

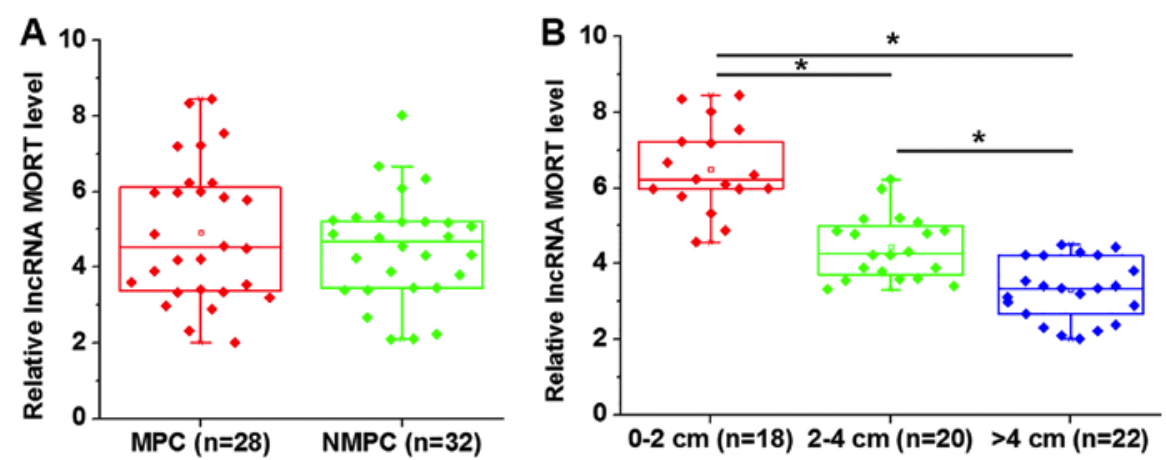

Figure 2. Expression of IncRNA MORT in tumor tissues is affected by tumor size, but not tumor metastasis. (A) No differences in the expression levels of lncRNA MORT in tumor tissues were observed between the MPC and NMPC groups, while (B) decreased lncRNA MORT expression was associated with an increase in tumor size. "P<0.05. IncRNA MORT, long non-coding RNA mortal obligate RNA transcript; MPC, metastatic prostate carcinoma; NMPC, non-metastatic prostate carcinoma.

$4 \mathrm{~h}$ at $37^{\circ} \mathrm{C}$. Dimethyl sulfoxide $(10 \mu \mathrm{l})$ was added to each well and optical density values were obtained at $450 \mathrm{~nm}$ using CLARIOstar Plus Plate Reader (BMG Labtech, Ltd.).

Western blot analysis. Following a 24-h transfection period, radioimmunoassay buffer (Thermo Fisher Scientific, Inc.) was used to extract the total protein from in vitro cultured cells. Protein concentrations were determined using a bicinchoninic acid assay. Proteins were denatured and separated using $12 \%$ SDS-PAGE with $30 \mu \mathrm{g} /$ lane. Following protein transfer to PVDF membranes, the membranes were blocked using $5 \%$ non-fat milk for $1 \mathrm{~h}$ at room temperature, followed by incubation with the following primary antibodies: Rabbit anti-human GLUT-1 (1:1,200; cat. no. ab32551, Abcam, Cambridge, UK) and GAPDH (1:1,000; ab8245, Abcam) at $4^{\circ} \mathrm{C}$ for $18 \mathrm{~h}$. The membranes were washed and subsequently incubated with goat anti-rabbit immunoglobulin G-horseradish peroxidase-conjugated secondary antibody $(1: 1,000$, MBS435036, MyBioSource, Inc., San Diego, CA, USA) at $24^{\circ} \mathrm{C}$ for $2 \mathrm{~h}$. Signals were developed using an enhanced chemiluminescence detection reagent (Sigma-Aldrich; Merck $\mathrm{KGaA}$ ), and the data were normalized using Image J v1.8.0 software (National Institutes of Health, Bethesda, MD, USA).

Statistical analysis. All experiments were performed in triplicate, and the data are presented as the mean \pm standard deviation. All statistical analyses were performed using SPSS software (version 19.0; IBM Corp., Armonk, NY, USA). For IncRNA MORT and GLUT-1 expression, data were normalized to the sample with the lowest value, which was set to 1 . For cell proliferation, the data were normalized to the control group, which was set to 100. Comparisons between IncRNA MORT expression levels in tumor tissues and adjacent healthy tissues were determined using a paired Student's t-test. Comparisons among three groups were performed using one-way analysis of variance followed by a Tukey's test. $\mathrm{P}<0.05$ was considered to indicate a statistically significant difference.

\section{Results}

IncRNA MORT is downregulated in tumor tissues, compared with the adjacent healthy tissues of patients with prostate carcinoma. The expression levels of lncRNA MORT in the tumor tissues of patients with prostate carcinoma were detected using RT-qPCR. Compared with adjacent healthy tissues, expression levels of lncRNA MORT were significantly downregulated in tumor tissues (Fig. 1). In addition, no significant differences in IncRNA MORT expression were observed between patients at different cancer stages (data not shown).

Expression of IncRNA MORT in tumor tissues is influenced by tumor size, but not tumor metastasis. Among the 60 patients with prostate carcinoma, there were 28 cases of metastatic prostate carcinoma (MPC) and 32 cases of non-metastatic prostate carcinoma (NMPC). No significant differences in the expression level of lncRNA MORT in tumor tissues were revealed between the MPC and NMPC groups (Fig. 2A). There were 18 patients with a primary tumor of $0-2 \mathrm{~cm}, 20$ cases between $2-4 \mathrm{~cm}$ and 22 cases $>4 \mathrm{~cm}$. A decrease in the level of IncRNA MORT expression was associated with an increase in tumor size (Fig. 2B; $\mathrm{P}<0.05$ ).

Overexpression of IncRNA MORT inhibits glucose uptake and GLUT-1 expression in the prostate carcinoma cell line 22Rv1. The overexpression rate of IncRNA MORT and GLUT-1 reached 200 and $300 \% 24$ h post-transfection, respectively (Fig. S1). Compared with the control and negative control groups, lncRNA MORT overexpression resulted in significantly reduced glucose uptake (Fig. 3A) and inhibited GLUT-1 expression (Fig. 3B) $(\mathrm{P}<0.05)$. Furthermore, GLUT-1 overexpression promoted glucose uptake, and attenuated the effects of IncRNA MORT overexpression on glucose uptake (Fig. 3A; P<0.05). However, GLUT-1 overexpression did not significantly effect lncRNA MORT expression (Fig. 3C; $\mathrm{P}>0.05$ ). Glucose uptake levels were consistent with GLUT-1 protein levels (Fig. 3D).

Overexpression of IncRNA MORT inhibits cell proliferation by suppressing GLUT-1. Compared with the control and negative control groups, overexpression of lncRNA MORT significantly inhibited, whilst GLUT-1 overexpression promoted the proliferation of 22Rv1 cells (Fig. 4; P<0.05). In addition, GLUT-1 overexpression attenuated the effects of IncRNA MORT on cell proliferation $(\mathrm{P}<0.05)$. 

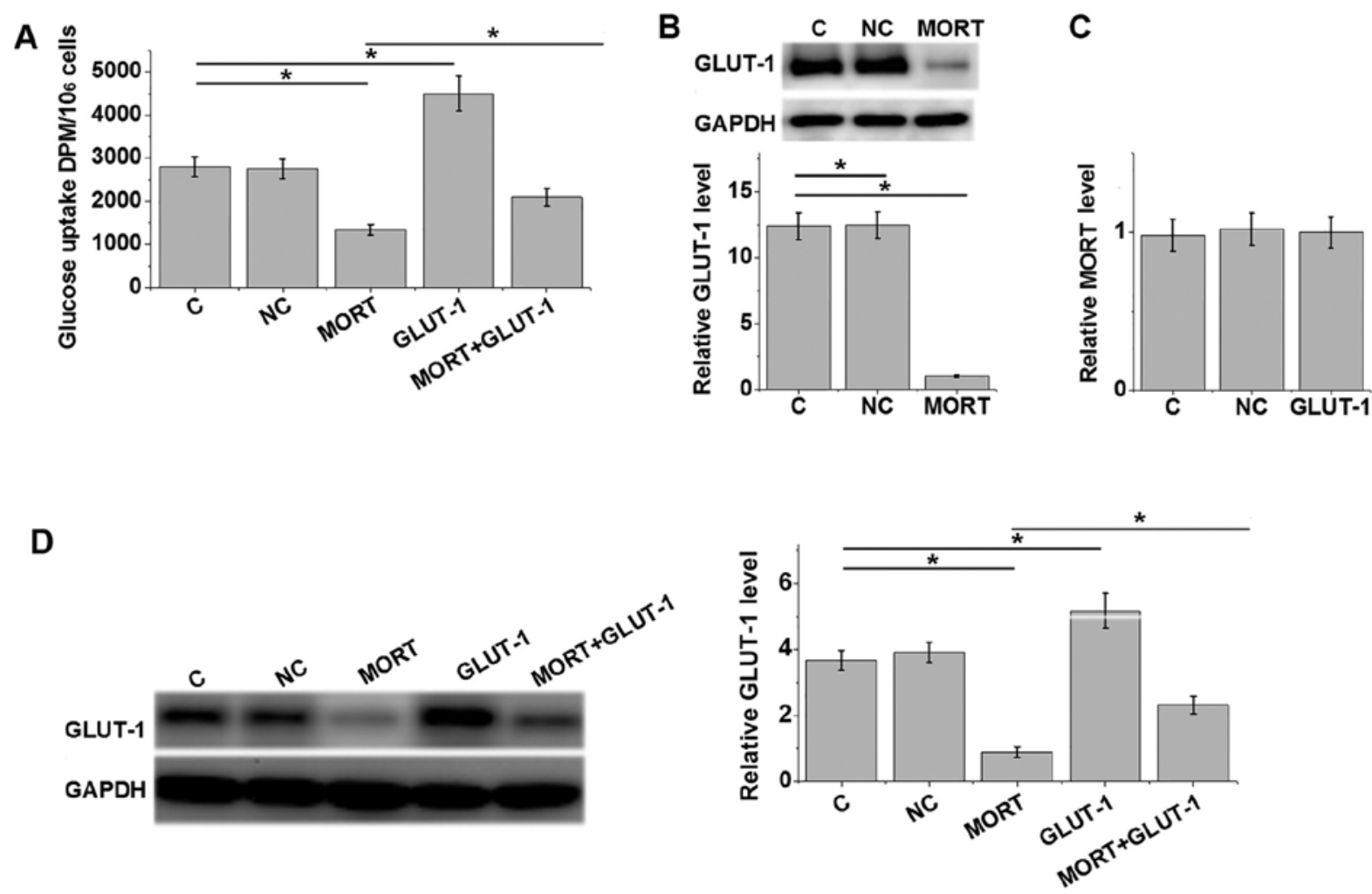

Figure 3. Overexpression of lncRNA MORT inhibits glucose uptake and GLUT-1 expression in the prostate carcinoma cell line 22Rv1. Glucose uptake assay and western blot analysis demonstrated that lncRNA MORT overexpression resulted in (A) significantly reduced glucose uptake and (B) and GLUT-1 expression. GLUT-1 overexpression promoted glucose uptake, and attenuated the effects of lncRNA MORT overexpression on glucose uptake. However, (C) GLUT-1 overexpression did not significantly affect lncRNA MORT expression, as revealed using reverse transcription-quantitative polymerase chain reaction. In addition, (D) western blot analysis illustrated that GLUT-1 mRNA and protein expression were promoted following GLUT-1 uptake, which was associated with glucose uptake. "P<0.05. IncRNA MORT, long non-coding RNA mortal obligate RNA transcript; GLUT-1, glucose transporter 1; C, control; NC, negative control.

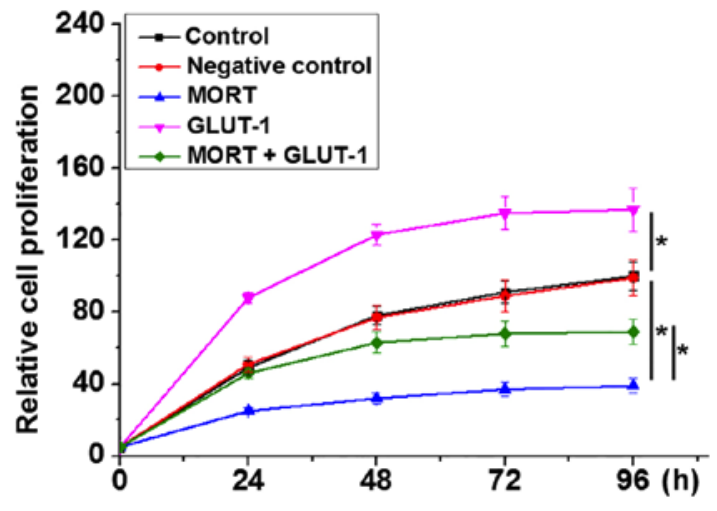

Figure 4. Overexpression of lncRNA MORT inhibits cell proliferation by retarding GLUT-1. Cell proliferation assays revealed that overexpression of lncRNA MORT significantly inhibited, while GLUT-1 overexpression promoted the proliferation 22Rv1 cells. In addition, GLUT-1 overexpression attenuated the effects of lncRNA MORT on cell proliferation. ${ }^{*} \mathrm{P}<0.05$. lncRNA MORT, long non-coding RNA mortal obligate RNA transcript; GLUT-1, glucose transporter 1.

\section{Discussion}

Glucose metabolism is critical for the development and progression of all types of cancers. The present study indicated that IncRNA MORT, a recently identified lncRNA which is silenced in 16 types of cancer (12), is downregulated in prostate carcinoma. In addition, lncRNA MORT may inhibit the proliferation of prostate carcinoma cells by inhibiting glucose uptake.

The development and progression of prostate carcinoma influences the expression of a large set of lncRNAs, a number of which have reported diagnostic or prognostic value $(14,15)$. In the present study, downregulated expression levels of lncRNA MORT were observed in prostate carcinoma tissues compared with adjacent healthy tissues. This supported preliminary microarray data revealing that lncRNA MORT was downregulated in prostate carcinoma tissues (data not shown). Notably, it was also revealed that the expression level of IncRNA MORT was effected by tumor size, but not tumor metastasis, indicating the potential involvement of IncRNA MORT in prostate tumor growth. This was further confirmed by the in vitro proliferation assay.

GLUT-1-mediated glucose uptake is associated with the abnormally accelerated proliferation of cancer cells $(16,17)$. Consistently, the present study revealed increased glucose uptake and prostate carcinoma cell proliferation following GLUT-1 overexpression. It is frequently been observed that glucose metabolism in human cancers is regulated by lncRNAs $(18,19)$. We reported significantly reduced glucose uptake and inhibited GLUT-1 expression in prostate carcinoma cells following lncRNA MORT overexpression. However, GLUT-1 overexpression failed to regulate lncRNA MORT. Therefore, IncRNA MORT may serve as a tumor suppressor in prostate carcinoma by inhibiting glucose uptake through 
the downregulation of GLUT-1. However, GLUT-1 mRNA levels were not significantly altered following lncRNA MORT overexpression (data not shown), suggesting that lncRNAs MORT may affect the level of GLUT-1 by regulating protein accumulation, rather than gene transcription.

It is worth noting that IncRNA MORT overexpression has not been reported to significantly affect any of the other GLUTs. Therefore, IncRNA MORT may specifically regulate GLUT-1 in prostate carcinoma. Due to limited resources, the present study only included one prostate cancer cell line. Future studies aim to include more cell lines to further support the conclusions drawn. The present study was also limited by a small sample population size. Future studies with a larger patient cohort are required to further verify the conclusions. Future studies will also focus on the diagnostic, prognostic and therapeutic value of IncRNA MORT in prostate carcinoma, which requires long-term follow-up studies in addition to an increased sample population.

In conclusion, IncRNA MORT was determined to be downregulated in prostate carcinoma and may inhibit tumor cell proliferation by suppressing glucose uptake. Therefore, IncRNA MORT may serve as a potential therapeutic target for prostate carcinoma.

\section{Acknowledgements}

Not applicable.

\section{Funding}

This study was supported by the Xinjiang Natural Science Foundation Funded Project (grant no. 2016D01C126), Xinjiang 'Tianshan Youth Project' 2017.

\section{Availability of data and materials}

The datasets used and/or analyzed during the current study are available from the corresponding author on reasonable request.

\section{Authors' contributions}

ZFS and FG conducted all of the experiments, analyzed all data and contributed to manuscript writing. DYJ, JXH, JC and MS also conducted experiments. FBQ was responsible for clinical studies of prostate cancer and clinical sample collection. CYL was responsible for experimental design and molecular studies. All authors read and approved the final manuscript.

\section{Ethics approval and consent to participate}

Ethics approval was obtained from the People's Hospital of Xinjiang Uyghur Autonomous Region, and all participants gave written informed consent.

\section{Patient consent for publication}

The study followed the tenets of the Declaration of Helsinki, and informed written consent was obtained from all patients and controls when the nature and possible consequences of the study were explained.

\section{Competing interests}

The authors declare that they have no competing interests.

\section{References}

1. Siegel RL, Miller KD and Jemal A: Cancer Statistics, 2017. CA Cancer J Clin 67: 7-30, 2017.

2. Gundem G, Van Loo P, Kremeyer B, Alexandrov LB, Tubio JMC, Papaemmanuil E, Brewer DS, Kallio HML, Högnäs G, Annala M, et al: The evolutionary history of lethal metastatic prostate cancer. Nature 520: 353-357, 2015.

3. US Preventive Services Task Force; Grossman DC, Curry SJ, Owens DK, Bibbins-Domingo K, Caughey AB, Davidson KW, Doubeni CA, Ebell M, Epling JW Jr, et al: Screening for prostate cancer: US preventive services task force recommendation statement. JAMA 319: 1901-1913, 2018.

4. Cheng L, Zincke H, Blute ML, Bergstralh EJ, Scherer B and Bostwick DG: Risk of prostate carcinoma death in patients with lymph node metastasis. Cancer 91: 66-73, 2001.

5. Fossa SD, Wiklund F, Klepp O, Angelsen A, Solberg A, Damber JE, Hoyer M and Widmark A; The Scandinavian Prostate Cancer Group-7 Investigators: Ten- and 15-yr prostate cancer-specific mortality in patients with nonmetastatic locally advanced or aggressive intermediate prostate cancer, randomized to lifelong endocrine treatment alone or combined with radiotherapy: Final results of the scandinavian prostate cancer Group-7. Eur Urol 70: 684-691, 2016.

6. Hay N: Reprogramming glucose metabolism in cancer: Can it be exploited for cancer therapy? Nat Rev Cancer 16: 635-649, 2016.

7. Semenza GL: Hypoxia-inducible factors: Coupling glucose metabolism and redox regulation with induction of the breast cancer stem cell phenotype. EMBO J 36: 252-259, 2017.

8. Olson AL and Pessin JE: Structure, function, and regulation of the mammalian facilitative glucose transporter gene family. Annu Rev Nutr 16: 235-256, 1996

9. Liu Y, Cao Y, Zhang W, Bergmeier S, Qian Y, Akbar H, Colvin R, Ding J, Tong L, Wu S, et al: A small-molecule inhibitor of glucose transporter 1 downregulates glycolysis, induces cell-cycle arrest, and inhibits cancer cell growth in vitro and in vivo. Mol Cancer Ther 11: 1672-1682, 2012.

10. Liu X and Gan B: lncRNA NBR2 modulates cancer cell sensitivity to phenformin through GLUT1. Cell Cycle 15: 3471-3481, 2016.

11. Fang Y and Fullwood MJ: Roles, functions, and mechanisms of long Non-coding RNAs in cancer. Genomics Proteomics Bioinformatics 14: 42-54, 2016.

12. Vrba L and Futscher BW: Epigenetic silencing of lncRNA MORT in 16 TCGA cancer types. F1000Res 7: 211, 2018.

13. Livak KJ and Schmittgen TD: Analysis of relative gene expression data using real-time quantitative PCR and the 2(-Delta Delta C(T)) method. Methods 25: 402-408, 2001.

14. Lee B, Mazar J, Aftab MN, Qi F, Shelley J, Li JL, Govindarajan S, Valerio F, Rivera I, Thurn T, et al: Long noncoding RNAs as putative biomarkers for prostate cancer detection.J Mol Diagn 16: 615-626, 2014.

15. Wan X, Huang W, Yang S, Zhang Y, Pu H, Fu F, Huang Y, Wu H, $\mathrm{Li} \mathrm{T}$ and $\mathrm{Li} \mathrm{Y}$ : Identification of androgen-responsive lncRNAs as diagnostic and prognostic markers for prostate cancer. Oncotarget 7: 60503-60518, 2016.

16. Sawayama H, Ishimoto T, Watanabe M, Yoshida N, Baba Y, Sugihara H, Izumi D, Kurashige J and Baba H: High expression of glucose transporter 1 on primary lesions of esophageal squamous cell carcinoma is associated with hematogenous recurrence. Ann Surg Oncol 21: 1756-1762, 2014.

17. Gwak H, Haegeman G, Tsang BK and Song YS: Cancer-specific interruption of glucose metabolism by resveratrol is mediated through inhibition of Akt/GLUT1 axis in ovarian cancer cells. Mol Carcinog 54: 1529-1540, 2015.

18. Zheng X, Han H, Liu GP, Ma YX, Pan RL, Sang LJ, Li RH, Yang LJ, Marks JR, Wang W and Lin A: IncRNA wires up Hippo and Hedgehog signaling to reprogramme glucose metabolism. EMBOJ 36: 3325-3335, 2017.

19. Sun LY, Li XJ, Sun YM, Huang W, Fang K, Han C, Chen ZH, Luo XQ, Chen YQ and Wang WT: IncRNA ANRIL regulates AML development through modulating the glucose metabolism pathway of AdipoR1/AMPK/SIRT1. Mol Cancer 17: 127, 2018.

This work is licensed under a Creative Commons Attribution-NonCommercial-NoDerivatives 4.0 International (CC BY-NC-ND 4.0) License. 